\title{
Erectile Dysfunction: an Integrative Approach
}

Alain Bitton

$\begin{array}{ll} & * \text { Correspondence author } \\ & \text { Alain Bitton } \\ & \text { Men's Health and Andrology Clinic - } 95 \text { Route de } \\ \text { Urological Surgeon, Andrology and Men's Health Clinic, } \quad \begin{array}{l}\text { Florissant }-1206 \text { Genève } \\ \text { Switzerland } \\ \text { Switzerland }\end{array} & \text { Website : andrologue.com }\end{array}$

Submitted : 19 Dec 2020 ; Published : 28 Jan 2021

\begin{abstract}
For many years, integrative medicine has tried to provide a more global vision by integrating the different biological and physiological systems of the human body in the management of its dysfunctions. This approach, which appears quite new, allows a throughout integration of the diseases within a patient and no more despite the patient. It will be a question of integrating the patient's different organs into their body again in order to get to the heart of the problem in a metabolic and structured manner. This approach is quite interesting in urology as well and concerns number of pathologies like prostate, kidney and bladder diseases as well as functional problems. Moreover, certain new areas of concern like androgenic deficiencies as well as erectile dysfunction and ejaculatory problems are in the target of this new approach. It is at this level that integrative and functional medicine takes its place by allowing a global approach to the patient's problem and by focusing the initial care on the prevention of risk factors and natural and alternative treatments before prescription of chemical molecules.
\end{abstract}

Keywords: Global Approach, Urological Diseases, Integrative Medicine, Functional Medicine - Prevention - Natural and Alternative Treatments.

\section{Introduction}

Hippocrates was already saying "Make food your medicine". For more than 20 years, integrative medicine has tried to provide a more global vision by integrating the different biological and physiological systems of the human body in the management of its dysfunctions. This approach, which is thought to be new and which has even been accused of "reductive", is in fact only an update of a more global approach to medicine before the technology fragments and isolates the organs of the body by hyperspecializing their management. Today, it will be a question of integrating the patient's different organs into their body again in order to get to the heart of the problem in a metabolic and structured manner.

It is interesting to note that also in urology, integrative medicine has its place. The areas concerned are vast: benign hypertrophy and prostate cancer, diseases of the kidney and bladder (including stones) chronic prostatitis and pelvic dysfunction syndrome. As a first approach, we have chosen to focus on areas that particularly affect sexual health. In this article we will talk about erectile dysfunction. Age-Related Androgen Deficiency (AALD), commonly referred to as Andropause, will be discussed in a separate article.

\section{Erectile Dysfunction \\ Diagnostic Approach}

Since the advent of inhibitors of the enzyme Phosphodiesterase 5 (PDE-5) as first-line treatment, the medical profession has started to better understand and integrate the phenomenon of Erectile Dysfunction (ED) in a more global context of organic dysfunction and more specifically by its neuro-vascular pathways. This key symptom of cardiovascular disease affects nearly a third of men of all ages and almost one in two men from the age of 50 [1]. Physiologically, the guarantee of a quality erectile function must integrate a good neurovascular functioning at the level of the smooth muscle cell of the endothelium of the cavernous body of the penis, mediated in particular by an essential neurotransmitter, NO (nitric oxide). Any inflammatory disturbance in the functioning of the endothelium will consequently lead to a disturbance, sometimes irreversible, of the small penile arteries. It therefore appears that the assessment of an erectile dysfunction, whatever its etiology, constitutes a major diagnostic window of opportunity for all cardiovascular diseases and especially for the quality of the vascular endothelium. In his diagnostic approach, the doctor should therefore direct his anamnesis and his first clinical and paraclinical examinations to search for organ diseases and especially cardiovascular diseases (heart disease, coronary and hypertensive diseases) without forgetting dyslipidemias such as diabetes or metabolic syndrome. In patients with symptoms of testosterone deficiency or after 50 years of age, 
hypogonadism should be checked (clinical examination and blood testosterone dosage). In fact, the prevalence of male hypogonadism is estimated to be 5 to $15 \%$, increasing with age $[2,3]$.

\section{Integrative Approach}

Prevention above all

New data from integrative medicine, particularly in metabolic cardiology, highlight the essential role of prevention focusing on well-known risk factors such as hypertension, coronary heart disease and metabolic diseases, including hypercholesterolemia and dyslipidemias. Concerning the deleterious role of cholesterol, in particular the "bad" LDL cholesterol, reputed to be atherogenic, the latter should in fact be qualified given the fact that it is above all the particles of cholesterol which have become inflammatory which would be problematic and not cholesterol per se.

In any case, it should be mentioned that any erectile dysfunction in the endothelium of the smooth muscle cell of the cavernous body results from a more general dysfunction in the vascular endothelium throughout the body. It will therefore be necessary to act on the risk factors and promote a balanced diet with a reduction in inflammatory phenomena, in particular to reduce insulin resistance by avoiding all sugars and in particular fructose, to act on weight loss with a correction of the BMI (Body Mass index) and fat mass, regular physical exercise (aerobic and anaerobic), even daily according to programs adapted to each. In addition, strict control of blood pressure is essential. The other important factors in the balance are the control of the hours of sleep, which should ideally be between 7 and 9 hours per night, as well as the reduction of the stressors. Some also mentioned exogenous factors which would behave like real endocrine destroyers by disrupting the proper functioning of certain endocrine glands in the body (thyroid, pituitary, and pancreas). To this end, we must mention the toxic and surrounding pesticides as well as female hormones (contraceptive pills) discharged into the water.

\section{Drug Treatments}

\section{5-Phosphodiesterase (PDE-5) Inhibitors}

Once the prevention and correction program for possible risk factors is in place, drug treatments can be considered. These drugs, led by Sildenafil, Tadalafil and Vardenafil, are the most effective and commonly prescribed treatments for $\operatorname{ED}[4,5,6]$.

Apart from a few structural differences concerning the side effects or the duration of action [Table 1], these molecules have the same mode of operation: relaxation of the smooth muscle cell of the cavernous endothelium by inhibiting the degradation of 5-phosphodiesterase [Figure 1]. This results in an extension of the vascular relaxation and the filling time of the cavernous body allowing a quality erection.

\begin{tabular}{|l|l|l|l|l|}
\hline Molecule & Dosages & Deadline for action & Duration of action & Precautions \\
\hline Sildenafil (Viagra) & 25,50 or $100 \mathrm{mg}$ & $15-60 \mathrm{~min}$ & $8-15$ hours & $\begin{array}{l}\text { Watch out for taking nitrates, } \\
\text { certain hypotensive drugs and } \\
\text { alpha-blockers }\end{array}$ \\
\hline Vardénafil (Levitra) & $\begin{array}{l}10 \text { or } 20 \mathrm{mg}, 10 \mathrm{mg} \\
\text { sublingual form }\end{array}$ & $30 \mathrm{~min}$ & $8-15$ hours & Same comment \\
\hline Tadalafil (Cialis) & $2.5,5,10 \mathrm{or} 20 \mathrm{mg}$ & $15-45 \mathrm{~min}$ & $16-36$ hours & Same comment \\
\hline
\end{tabular}

Table 1: Characteristics of 5-Phosphodiesterase (PDE-5) inhibitors. [7, 8]

Since the discovery of Sildenafil in 1998 (particularly during research on the contractility of the heart smooth muscle cell), and other similar molecules, PDE5 inhibitors have been widely prescribed to millions of people around the world. The results are excellent in terms of functioning and quality of life. When the indications and especially the contraindications are well respected, these treatments are safe, very well tolerated and widely used.

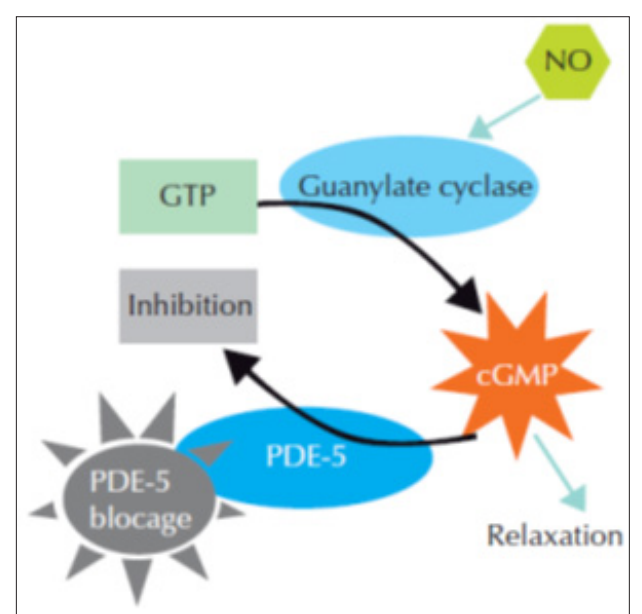

Figure 1: Mechanisms of action of PDE-5 inhibitors 
Intracavernous Prostaglandin Injections (Caverject, Edex)

Prostaglandin E1 or Alprostadil is used as a diagnostic injection or self-injection by the patient himself into the cavernous body, when oral drugs are not effective enough [Figure 2].

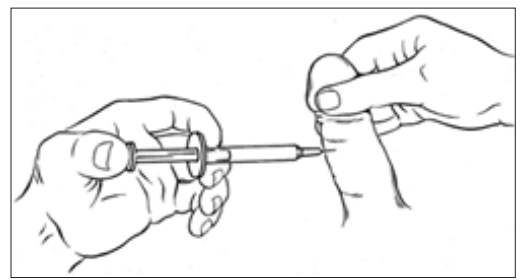

Figure 2: Principle of intracavernous injections according to M. M Newell \& L. Lemay Augusta Medical Systems Research \& Education Center.

This mainly concerns severe erectile dysfunction and sometimes diabetic patients or after pelvic radical surgery for prostate cancer. Thanks to a very easy-to-use plunger, the patient can prepare their syringe themselves and adapt the dosage (from 5 to 20 micrograms) as needed. The erection can last from 2 to 4 hours. Despite its effectiveness, the principle is not unanimous in particular because of the more invasive and less romantic aspect than taking a drug treatment which, when properly taken can be discreet, particularly with regard to the patient. or partner, which in no way disturbs the romantic relationship $[9,10]$. The injection can sometimes be painful at the puncture site. Care should be taken not to prick a vein and especially to consult urgently in case of priapism (prolonged painful erection despite ejaculation) endangering the vital prognosis of the organ.

Aprostadil can also be used as an intra-urethral suppository or instillation [(Muse; Figure 3)]. This form, containing 1,000 micrograms of prostaglandin, is easier to use but less effective than intracavernous injection and will mainly be used as an adjunct to other treatments.

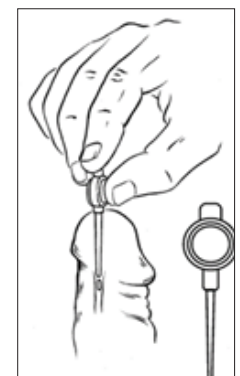

Figure 3: Aprostadil (prostaglandin) intra-urethral instillation according to M. M Newell \& L. Lemay Augusta Medical Systems - Research \& Education Center.

\section{Vacuum Pump (VACUUM, EREC-AID)}

For some more open and motivated patients, there is the possibility of using an erection support system in the form of a vacuum pump [Figure 4]. The system makes it possible to obtain an erection and then maintain it thanks to a constriction ring. These pumps are effective in ED, after pelvic surgery, radiotherapy or in cases of penile deviation such as Peyronie's disease $[11,12,13]$. Most patients are very satisfied and the pump is a good compromise for those who are unable or unwilling to take long-term medication or who are not ready for implantation of a penile prosthesis.

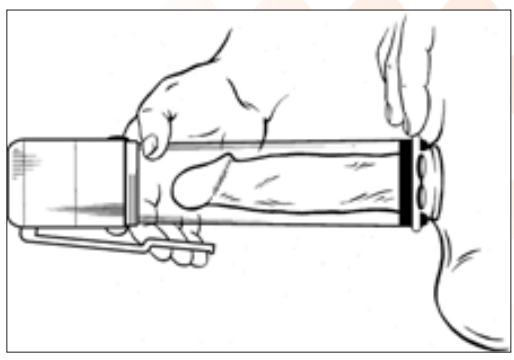

Figure 4: The vacuum pump according to M. M Newell \& L. Lemay Augusta Medical Systems - Research \& Education Center.

Food Supplements

For patients who wish to start a natural treatment before considering a chemical molecule, there is in the literature several scientific evidences of the effectiveness of certain substances, the main characteristics of which can be found in [Table 2]. It will obviously be necessary to be careful with these prescriptions even if they are "natural", because the Internet abounds in divergent opinions and the very numerous sites which recommend them without medical follow-up are not always reliable. It should also be mentioned that globally these treatments are reserved for cases of slight or moderate dysfunction [14].

The use of dietary supplements can also be extremely beneficial for the purpose of improving or preserving endothelial function, as mentioned in metabolic cardiology. The recommended and most commonly used substances are Coenzyme Q10, Selenium, L-Carnitine, Magnesium as well as vitamins C, D and $\mathrm{E}$ among others. The intake of these treatments, although of natural origin, should always be supervised by a competent doctor. 


\begin{tabular}{|l|l|l|l|l|}
\hline Molecule & Dosage & Mechanism & Precaution & Note \\
\hline Panax Ginseng & $900 \mathrm{mg} 3 \mathrm{x} / \mathrm{j}$ & $\begin{array}{l}\text { Increases the activity } \\
\text { of NO }\end{array}$ & $\begin{array}{l}\text { Insomnia, heart rhythm } \\
\text { disturbances }\end{array}$ & $\begin{array}{l}\text { In cream can be used for } \\
\text { premature ejaculation }\end{array}$ \\
\hline Yohimbine & $5-10 \mathrm{mg} 3 \mathrm{X} / \mathrm{j}$ & $\begin{array}{l}\text { MAO inhibitor, anti- } \\
\text { calcium }\end{array}$ & $\begin{array}{l}\text { Mood disorders, kidney / } \\
\text { liver dysfunction, BPH }\end{array}$ & $\begin{array}{l}\text { Careful and medically } \\
\text { controlled use }\end{array}$ \\
\hline L-Arginine & $1000-2000 \mathrm{mg} 3 \mathrm{x} / \mathrm{j}$ & Precursor of NO & Gout, asthma, GI disorders & $\begin{array}{l}\text { Additive effect if taken } \\
\text { pycnogenol }\end{array}$ \\
\hline Pycnogenol & $40 \mathrm{mg} 3 \mathrm{x} / \mathrm{j}$ & $\begin{array}{l}\text { Activation of NO } \\
\text { synthesis }\end{array}$ & $\begin{array}{l}\text { Dizziness, anticoagulants, } \\
\text { GI disorders }\end{array}$ & $\begin{array}{l}\text { Improves the effect of } \\
\text { sildenafil }\end{array}$ \\
\hline $\begin{array}{l}\text { Propionyl-L } \\
\text { carnitine }\end{array}$ & $1000 \mathrm{mg} 2 \mathrm{x} / \mathrm{j}$ & $\begin{array}{l}\text { Anti-inflammatory, } \\
\text { potentiates the effect } \\
\text { of NO }\end{array}$ & $\begin{array}{l}\text { Gastrointestinal }(\mathrm{GI}) \\
\text { Disorders }\end{array}$ & $\begin{array}{l}\text { Anticoagulants, GI } \\
\text { disorders }\end{array}$ \\
\hline Ginkgo biloba & $60-120 \mathrm{mg} 2 \mathrm{x} / \mathrm{j}$ & Flavonoid effect & & \\
\hline
\end{tabular}

Table 2: The table below presents the natural elements recognized as effective in the treatment of ED [15].

\section{Alternative Medicine}

We still lack perspective on the effectiveness of certain alternative therapies in the treatment of ED, such as acupuncture or massage therapy [16]. Certain manipulations in chiropractic or osteopathy have allowed some improvement in pelvic-perineal symptoms in the management of inflammatory prostatitis often associated with ED in young patients.

As a new method of non-invasive treatment, we must also mention transcutaneous hyperthermia (i-wave / Thermowave), which allows through the application of heat externally (by the mean of radiofrequency waves and neuromodulation) and in stages at $44^{\circ} \mathrm{C}$ in the perineal, bladder and prostate areas, a redistribution of vascularization and improved blood flow to the penis and perineum. This not only improves the symptoms of prostatitis or pelvic-perineal dysfunction, but also increases sexual performance by regulating blood flow to the small arteries of the genitals. The first clinical experiences of the author (data to be published) on this subject are extremely promising.

\section{Body-Mind Integration}

Sexual desire, libido and orgasm are mediated by complex psycho-neurological mechanisms [Figure 5]. It all starts at the brain centers of the hypothalamus where desire is generated and integrated. Then, there will be a relay at the level of the thoracolumbar sympathetic center of the erection, from the parasympathetic sacral reflexogenic center to the distal effector which is located at the level of the external genitalia, including the penis.

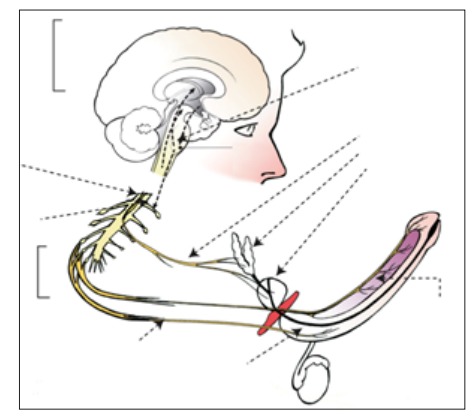

Figure 5: Neuro-physiological control of erection and ejaculation [17].
It is important to remember that although the anatomical and pathophysiological substrate of sexual dysfunction is very real, the psychological aspect often takes precedence. Indeed, the brain counts the failures and sexual breakdowns can lead to doubt, anxiety, lack of self-confidence in men and sometimes even depression. This will obviously have to be taken into account in the diagnostic and therapeutic management of the patient and especially in the couple's therapy approach.

\section{Action on Risk Factors}

As already mentioned, ED can be considered an early symptom (appearing on average 2 to 3 years before the onset of the condition in question) of chronic diseases such as cardiovascular disorders or dyslipidemias $[18,19,20]$. It should also be mentioned that even if certain cardiovascular diseases such as hypertension are well controlled by taking drugs, the latter are the primary culprits of drug-induced ED due to the decrease in blood pressure in the small penile arteries [21].

Apart from hypertension, the famous metabolic syndrome plays an essential role in the pathogenesis of ED [22, 23, 24]. In men with diabetes the prevalence of ED is high to almost $89 \%$, while obesity defined by a BMI greater than 30 doubles the risk of developing ED. Consuming alcohol and tobacco on a regular basis also significantly increases the risk of ED. For all these reasons, it will be imperative to correct cardiovascular risk factors as well as metabolic disorders. It is also important to understand that the aforementioned chronic diseases rarely appear overnight. There is a kind of metabolic "continuum" along which the patient progresses and first presents progressively greater insulin resistance before developing diabetes or a metabolic syndrome. The principle is the same for hypertension. A patient may begin to develop inflammatory stiffness in the arteries of the body even with blood pressure considered normal $(130 / 80 \mathrm{~mm} \mathrm{Hg})$, before hypertension sets in sneakily and silently. Erectile dysfunction is often the only and early symptom. It is therefore at this level that we must act to correct the risk factors and adapt the lifestyle by controlling the diet, removing pro-inflammatory dietary or environmental factors and regular physical exercise. Proactive action in this window of opportunity will thus prevent the patient from 
entering an irreversible state of global endothelial dysfunction which will manifest as erectile and then sexual dysfunction [25].

In the field of food, particular emphasis is placed on the application of a so-called Mediterranean diet (famous Okinawa diet), promoting polyunsaturated fats and oils of the omega-3 and omega- 6 type. We find in olive oil, the regular intake of fresh fruits and vegetables and the reduction or even the elimination of refined pastes and sugars, stimulants such as coffee or tobacco [26].

\section{New Therapies}

New treatments are being studied, in particular thanks to research targeting arginase inhibitors. This enzyme has selective competition for NO at the level of L-arginine. Increased expression and activity of arginase in the corpora cavernosa has been shown, which may explain ED. Selective inhibition of arginase would increase arterial blood flow to the penis [27].

Gene therapy is also a booming and very promising field. Ongoing research is targeting arginase, in particular using markers such as Rho A / Rho-kinase (ROCK) and p38-MAPK. Another example includes work on the Maxi-K protein (MKPG) gene expressed as a potassium ion channel whose function is to initiate and maintain erection thanks to an ionic gradient on both sides of the smooth muscle cell of the cavernous body $[28,29,30]$. All of these findings would open the door to a whole new gene therapy in the treatment of erectile dysfunction. These treatments, if they become operational, could be used alone or in combination with 5-Phosphodiesterase inhibitors and would have the advantage of being able to be prescribed without significant risk to patients on nitrates or other cardiac medications. Gene therapy might also not have the invasive and unromantic inconvenience of intracavernous injections.

\section{Conclusion}

Even if there are very effective drugs to treat ED, the prevention of the risk factors that constitute cardiovascular and metabolic diseases plays a major role here by preserving on the one hand the metabolic health of man but, on the other hand, by avoiding the development of an erectile dysfunction which is extremely distressing for the patient which risks causing frustration, problems in the couple with loss of self-esteem and identity sometimes leading to a breakup. It is at this level that integrative and functional medicine takes its place by allowing a global approach to the patient's problem and by focusing the initial care on the prevention of risk factors and natural and alternative treatments before prescription of chemical molecules.

\section{References}

1. Constance G Bacon, Murray A Mittleman, Ichiro Kawachi, Edward Giovannucci, Dale B Glasser, Eric B Rimm (2003) Sexual Function in Men Older Than 50 Years of Age: Results from the Health Professionals Follow-Up Study. Ann Intern Med 139: 161-168. doi: 10.7326/00034819-139-3-200308050-00005

2. Salom MG, Jabaloyas JM (2010) Testosterone Deficit Syndrome and Erectile Dysfunction. Arch Esp Urol 663: 670.

3. Shabsigh R, Kaufman JM, Steidle C, H Padma-Nathan. Randomized Study of Testosterone Gel as Adjunctive Therapy to Sildenafil in Hypogonadal Men with Erectile Dysfunction Who Do Not Respond To Sildenafil Alone. J Urol. 2004; 172: 658-663. doi: 10.1097/01. ju.0000132389.97804.d7

4. Carson CC, Lue TF (2005) Phosphodiesterase Type 5 Inhibitors for Erectile Dysfunction. BJU Int 96: 257-280. doi: 10.1111/j.1464-410X.2005.05614.x

5. Vardi M, Nini A (2007) Phosphodiesterase Inhibitors for Erectile Dysfunction in Patients with Diabetes Mellitus. Cochrane Database Syst Rev 2007(1): CD002187. doi: 10.1002/14651858.CD002187.pub3

6. Rendell MS, Rajfer J, Wicker PA, Smith MD (1999) Sildenafil for Treatment of Erectile Dysfunction in Men with Diabetes: A Randomized Controlled trial. Sildenafil Diabetes Study Group. JAMA 281: 421-426. doi: 10.1001/ jama.281.5.421

7. Brant WO, Bella AJ, Lue TF (2007) Treatment Options for Erectile Dysfunction. Endocrinol Metab Clin North Am 36: 465-479. doi: 10.1016/j.ecl.2007.02.001

8. Palit V, Eardley I (2010) An update On New Oral PDE5 Inhibitors for The Treatment of Erectile Dysfunction. Nat Rev Urol 7: 603-609. doi: 10.1038/nrurol.2010.165

9. R Shabsigh, H Padma-Nathan, M Gittleman, J McMurray, J Kaufman, I Goldstein. (200) Intracavernous Alprostadil Alfadex is More Efficacious, Better Tolerated, and Preferred over Intraurethral Alprostadil Plus Optional Actis: A Comparative, Randomized, Crossover, and Multicenter Study. Urology 55: 109-113. doi: 10.1016/ s0090-4295(99)00442-2

10. Wayland Hsiao, Nelson Bennett, Patricia Guhring, Joseph Narus, John P Mulhall (2011) Satisfaction Profiles in Men Using Intracavernosal Injection Therapy. J Sex Med 8(2): 512-527. doi: 10.1111/j.1743-6109.2010.02093.x

11. R J Bosshardt, R Farwerk, R Sikora, M Sohn, G Jakse (1995) Objective Measurement of the Effectiveness, Therapeutic Success and Dynamic Mechanisms of the Vacuum Erection Device. Br J Urol 75: 786-791. doi: 10.1111/j.1464-410x.1995.tb07392.x

12. P G Katz, H T Haden, T Mulligan, N D Zasler (1990) The Effect of Vacuum Devices on Penile Hemodynamics. $J$ Urol 143: 55-56. doi: 10.1016/s0022-5347(17)39863-4

13. Geetu Pahlajani, Rupesh Raina, Stephen Jones, Marwan Ali, Craig Zippe (2012) Vacuum Erection Devices Revisited: Its Emerging Role in The Treatment of Erectile Dysfunction and Early Penile Rehabilitation Following 
Prostate Cancer Therapy. J Sex Med 9(4): 1182-1189. doi: 10.1111/j.1743-6109.2010.01881.x

14. R. Shamloul: Natural Aphrodisiacs. $J$ Sex Med 2010; 7: 3949. doi:https://doi.org/10.1111/j.1743-6109.2009.01521.x

15. L. Fortney in "Integrative Medicine » by David Rakel, Fourth Edition, 2018 Chapter 63 p. 627.

16. Myeong Soo Lee, Byung-Cheul Shin, Edzard Ernst (2009) Acupuncture For Treating Erectile Dysfunction: A Systematic Review. BJU Int. 2009; 104: 366-370. doi: 10.1111/j.1464-410X.2009.08422.x

17. Giuliano \& Clement. Eur Urol 2006; 50(3): 454-466.

18. John B Kostis 1, Graham Jackson, Raymond Rosen, Elizabeth Barrett-Connor, Kevin Billups, Arthur L Burnett, et al. (2005) Sexual Dysfunction and Cardiac Risk (the Second Princeton Consensus Conference). Am J Cardiol 96: 313-321. doi: 10.1016/j.amjcard.2005.03.065

19. Ian M Thompson, Catherine M Tangen, Phyllis J Goodman, Jeffrey L Probstfield, Carol M Moinpour, Charles A Coltman (2005) Erectile Dysfunction and Subsequent Cardiovascular Disease. JAMA 294(23): 2996-3002. doi: 10.1001/jama.294.23.2996

20. Kew-Kim Chew, Judith Finn, Bronwyn Stuckey, Nicholas Gibson, Frank Sanfilippo, Alexandra Bremner, et al. (2010) Erectile Dysfunction as a Predictor for subsequent atherosclerotic cardiovascular events: Findings From a Linked-Data Study. J Sex Med 07: 192-202. doi: 10.1111/j.1743-6109.2009.01576.x

21. SG Chrysant (2015) Antihypertensive Therapy Causes Erectile Dysfunction. Curr Opin Cardiol 30: 383-390. doi: 10.1097/HCO.0000000000000189

22. Binhan Kagan Aktas, Cevdet Serkan Gokkaya, Suleyman Bulut, Mehmet Dinek, Cuneyt Ozden, Ali Memis (2010) Impact of Metabolic Syndrome on Erectile Dysfunction and Lower Urinary Tract Symptoms in Benign Prostatic Hyperplasia Patients. Aging Male14: 48-52. doi: 10.3109/13685538.2010.529197

23. Carol A Holden 1, Carolyn A Allan, Robert I McLachlan (2010) Windows of Opportunity: A Holistic Approach to Men's Health. Med J Aust 192(12): 708-711.

24. O E el-Rufaie 1, A Bener, M S Abuzeid, T A Ali (1997) Sexual Dysfunction among Type II Diabetic Men: A Controlled Study. J Psychosom Res 43(6): 605-612. doi: 10.1016/s0022-3999(97)00183-9

25. J. Taylor (2015) Mediterranean Diet Linked to Improved Cardiovascular Function In Erectile Dysfunction Patients. Eur Heart J 36: 836.

26. David S. Lopez, Run Wang, Konstantinos K. Tsilidis, Huirong Zhu, Carrie R. Daniel, Arup Sinha, et al (2015) Role of Caffeine Intake on Erectile Dysfunction in Us Men: Results from NHANES 2001-2004. PLoS One 10: 4. doi: 10.1371/journal.pone. 0123547

27. Haroldo A Toque, Robert William Caldwell (2014) New Approaches to the Design and Discovery of Therapies to Prevent Erectile Dysfunction. Expert Opin Drug Discov 9: 1447-1469. doi: 10.1517/17460441.2014.949234

28. G.J. Christ, K. Andersson, K. Williams (2008) Restoration of Erectile Function and Sexual Behavior in Atherosclerotic Monkeys Following Maxi-K Gene
Transfer with a Smooth Muscle-Specific Promoter. J Urol. 2008; 179 (Suppl): 425.

29. Arnold Melman, Kelvin P Davies, Andrew R McCullough, Natan Bar-Chama, and George J Chris (2008) LongTerm Safety Follow up of a Phase I Trial for Gene Transfer Therapy of ED with hMaxi-k. J Urol. 2008; 179 (Suppl): 426-430.doi: https://doi.org/10.1016/S00225347(08)61249-5

30. H. Porst (2010) The Future of Erectile Dysfunction (ED). Arch Esp Urol 63: 740-747.
Copyright: (C2021 Alain Bitton. Snyder. This is an open-access article distributed under the terms of the Creative Commons Attribution License, which permits unrestricted use, distribution, and reproduction in anymedium, provided the original author and source are credited. 